РАСТОРГУЕВ Сергей Викторович - доктор политических наук; профессор департамента политологии и массовых коммуникаций Финансового университета при Правительстве РФ (125993, Россия, г. Москва, ГСП-3, Ленинградский пр-кm, 49; SRastorguev@fa.ru)

\title{
ФАКТОРЫ, РЕСУРСЫ, СТРАТЕГИИ ИНТЕНСИВНОГО ЭКОНОМИЧЕСКОГО РОСТА СОВРЕМЕННОЙ РОССИИ: ПОЛИТИЧЕСКИЙ АНАЛИЗ
}

\begin{abstract}
Аннотация. Данная статья посвящена анализу перспектив трансформации экономической политики российской политической и бизнес-элит в условиях «посткрымской нормальности», внешнего режима антироссийских санкций, волатильности цен на мировых рынках сырья. Автор анализирует возможности перехода «господствующей коалиции» к замещению части доходов от внешнеэкономических операций по экспорту сырья доходами от развития отраслей торгуемых и неторгуемых секторов внутреннего рынка в результате применения бизнес-стратегии «голубого океана». Устанавливается корреляция выбранных автором отраслей экономики и отраслевых ниш с приоритетными национальными проектами, анонсированными президентом РФ и детализированными правительством РФ в паспортах национальных проектов в 2018-2019 гг. Особое внимание автор уделяет выявлению внутренних источников финансирования проектов для интенсификации экономического роста со стороны государства, фирм, домохозяйств. Автор обосновывает вывод, что Российская Федерация располагает достаточным финансовым, технологическим, кадровым, сырьевым потенциалом для достижения нового качества жизни граждан к 2024 г. при условии консенсуса элитных групп и реализации стратегии «легкого подталкивания» акторов политики и экономики со стороны лидеров «господствующей коалиции».

Ключевые слова: факторы интенсивного экономического роста, «господствующая коалиция», государственные инвестиции, внутренний рынок, национальные проекты
\end{abstract}

$\mathrm{B}$ представленной статье экономический рост связывается с государственной экономической политикой в форме бюджетных инвестиций в рамках национальных проектов, рыночной мобилизацией финансовых ресурсов фирм и домохозяйств. Ряд исследований доказывает наличие положительной корреляции между ростом государственных расходов по статьям «Национальная экономика», «Образование» и увеличением реального ВВП. Одновременно указывается, что обратная корреляция имеет место при росте бюджетных расходов по статьям «Национальная оборона», «Социальная политика» [Вотинов, Станкевич 2017: 73]. В других работах устанавливается положительная корреляция бюджетных расходов и экономического роста для всех статей государственных расходов [Баранов, Крашенина 2016]. Поскольку для исполнения майских указов 2018 г. Президента РФ потребуется распределять ограниченные ресурсы среди 13 национальных проектов, ряд которых носят межотраслевой характер, перед «господствующей коалицией» стоит задача поиска Паретоэффективности в условиях «новой нормальности посткрымского консенсуса».

Выбор отраслевых ниш для приоритетного бюджетного финансирования анализируется в рамках концепции бизнес-стратегии «голубого океана» Ким Чана и Рене Моборна, предполагающей создание новой отраслевой ниши, новой ценности для клиента на основе модели четырех действий в отношении отраслевых факторов: это упразднение - снижение - повышение - создание отраслевых факторов [Чан Ким, Моборн 2014: 48].

В условиях антироссийских санкций, волатильности мировых рынков сырья, перестройки системы международных отношений в многополярную конфигурацию перед политической и бизнес-элитами России встают 3 задачи трансформации экономического роста: замещение части факторов экстенсивного 
роста факторами интенсивного экономического роста, использование преимущественно внутренних ресурсов для инвестиций, поиск «голубых океанов» на внутренних и зарубежных рынках. Все указанные трансформации носят политико-экономический характер, поскольку в условиях режима «ручного управления», вертикали власти, значительной доли государственного сектора экономики (вклад государственного сектора в ВВП России можно приблизительно оценить в 46\%) [Абрамов и др. 2018: 38] и неокорпоративистской встроенности крупного российского бизнеса в политическое пространство от «господствующей коалиции» для сохранения власти и собственности, для результативного и эффективного управления страной потребуются консолидированные решения и действия.

Экстенсивный рост, основанный на увеличении количества задействованных в производстве трудовых, сырьевых, капитальных ресурсов, имеет свои пределы роста как в силу ограниченности или труднодоступности новых ресурсов, так и в силу естественных и искусственных ограничений на внутреннем и зарубежных рынках. Объективные демографические тренды сокращают трудоспособное население России на полмиллиона человек ежегодно, износ основных фондов промышленности и инфраструктуры требует не капитального ремонта, а массового обновления, объемы добычи минерального сырья ограничиваются как темпами ввода новых месторождений, так и волатильностью мировых цен, обесценивающих увеличение добычи. «Газовые войны» в Европе демонстрируют, что политические и стоящие за ними финансовые интересы антироссийских групп давления могут перевесить экономическую выгоду стран - импортеров российского сырья. Вместо свободной конкуренции создаются «Политические рынки». Крупнейшие сырьевые компании России ПАО «Газпром» и ПАО «Лукойл» вследствие политического давления продают инфраструктурные активы в Центральной и Восточной Европе.

Существенная доля в ВВП и доходной части бюджета от производства на экспорт углеводородов и металлов ставит Россию в зависимость от мировой рыночной конъюнктуры и политической воли элит тех стран, которые закупают российское сырье. По данным ФТС, в 2017 г. экспорт РФ составил 357 млрд долл., таким образом, Россия экспортировала 24\% своего ВВП, из которых 59\% пришлось на продукцию ТЭК 1 . Для сравнения: экспортная квота Китая - 18\%, Японии - 14\%, Бразилии - 11\%, США - $8 \%$ с учетом иной структуры экспорта, в котором преобладают несырьевые товары и услуги. Чем сильнее экономика страны интегрирована в мировую торговлю или глобальную цепочку разделения труда, тем больше зависимость экономического роста от внешних факторов.

Анализ динамики добычи нефти, газа, угля в 2016-2018 гг. свидетельствует о том, что Россия продолжает наращивать добычу и экспорт энергоносителей ${ }^{2}$. Автор предполагает, что в контексте синтеза теории абсолютных преимуществ А. Смита и институциональной концепции траектории институциональных изменений Д. Норта [Норт 1997: 119-134] российская экономика в период 2019-2024 гг. при сохранении или существенном неухудшении санкционного формата останется преимущественно сырьевой, экстенсивной, экспортоориентированной. Прогнозы Министерства экономического развития РФ до 2024 г. также предполагают преимущественно экстенсивный рост ТЭК: рост

1 Экспорт-импорт важнейших товаров за январь-декабрь 2017 г. - Официальный сайт Федеральной таможенной службы. Доступ: http://www.customs.ru/index.php?option=com_content\&view= article\&id=26258 (проверено 03.11.2019).

2 Добыча и переработка основных видов полезных ископаемых. Россия в цифрах: краткий статистический сборник. М.: Росстат. С. 223. Доступ: http://www.gks.ru/free_doc/doc_2018/rusfig/rus18.pdf (проверено 03.11.2019). 
добычи нефти на 1,9\%, добычи газа - на 9,4\%, угля - на 10,1\% [Прогноз... 2018: 36-41]. При сохранении «господствующей коалицией» контроля над сырьевой рентой основные риски связаны с волатильностью доходов от экспорта. Минимизировать данные риски можно с помощью создания источников ренты на внутреннем рынке посредством перехода к экономическому росту, основанному в большей степени на интенсивных факторах и использовании стратегии «голубого океана».

Неоднократно ставившаяся задача перехода к интенсивному экономическому росту становится в политической повестке дня не идеологическим призывом, а мобилизационной стратегией «господствующей коалиции». Факторами интенсивного экономического роста являются повышение квалификации работников, а также новые технологии, которые повышают производительность труда, экономят ресурсы. Одной из основных угроз политической, социальной стабильности современной России является инерционное экономическое развитие: за период 2011-2016 гг., по расчету автора, экономический рост в постоянных ценах 2011 г. составлял в среднем $0,8 \% 1$.

Именно экономический рост наряду с эффективными бюджетными расходами позволяет поднять благосостояние населения, решать внутриполитические и внешнеполитические задачи без увеличения долговой нагрузки, роста налогового бремени, монетарной и немонетарной инфляции, исходящей от государства. Интенсивный экономический рост входит в противоречие с сырьевым характером российской экономики. Хотя для добычи и транспортировки углеводородов, угля, руды, производства черных и цветных металлов также нужны новые технологии, а повышение производительности труда приносит собственникам дополнительную прибыль, владельцы и топ-менеджеры фирм данных отраслей ориентированы прежде всего на благоприятную конъюнктуру мировых цен. Для создания и использования факторов интенсивного экономического роста они нуждаются не столько во внешнем ценовом шоке, сколько в «Подталкивании» со стороны властных групп современной России.

Любой вид экономического роста требует инвестиций со стороны фирм, государства, домохозяйств, иностранных акторов. По статистике Банка России, за 2014-2018 гг. чистый отток капитала из России составил примерно 320 млрд долл. Хотя действующая в стране методика расчета чистого ввоза и вывоза капитала включает в данную статью такие разноплановые компоненты, как погашение задолженности перед нерезидентами, рост иностранных активов компаний, реализация нерезидентами российских активов и государственного долга, покупка населением валюты, данный показатель свидетельствует, что Российская Федерация продолжает оставаться нетто-кредитором мировых рынков [Леонова 2017]. В условиях «посткрымской нормальности», согласно концепции окна Овертона, граница приемлемого и радикального в инвестиционной политике сдвигается в сторону последнего. Для ускоренного экономического роста на основе интенсивных факторов нужны внутренние финансовые ресурсы, которые имеются у трех субъектов - государства, фирм, домохозяйств, а для мобилизации внутренних ресурсов необходимы мотивы, воля, действия «господствующей коалиции».

Российское государство располагает инвестиционными ресурсами, которые сосредоточены в нескольких источниках. Федеральный бюджет РФ на 20192021 гг. предполагает расходы на национальные проекты в размере 5,7 трлн руб. Для пополнения федерального бюджета были проведены налоговые меропри-

\footnotetext{
${ }^{1}$ Национальные счета. Валовой внутренний продукт. - Официальный сайт Федеральной службы государственной статистики. Доступ: http://old.gks.ru/wps/wcm/connect/rosstat_main/rosstat/ru/ statistics/accounts/ (проверено 03.11.2019).
} 
ятия («налоговый маневр» в нефтяной отрасли, повышение НДС), организационные мероприятия (введение онлайн-касс), налоговое администрирование стало более жестким (по данным ФНС, в 2018 г. по сравнению с 2017 г. поступления в консолидированный бюджет РФ за январь-ноябрь 2018 г. выросли на $23,9 \%$ при росте ВВП в диапазоне $1,8-2 \%)^{1}$.

Золотовалютные резервы России составляли на февраль 2019 г. 531, 8 млрд долл. По достаточности международных резервов, которая рассчитывается как сумма, необходимая для покрытия трехмесячного импорта, РФ входит в топ-10 стран. При этом около $80 \%$ международных резервов вложены в ценные бумаги иностранных эмитентов или размещены на депозитах иностранных банков 2 . Учитывая относительно небольшой внешний государственный долг РФ 53,8 млрд долл. - и плавающий валютный курс Банка России, который не требует валютных интервенций для поддержки отечественной валюты, вопрос об использовании части международных резервов в инвестиционных целях представляется вопросом политического выбора «господствующей коалиции».

На октябрь 2019 г. размер Фонда национального благосостояния составил 123 млрд долл. ${ }^{3}$ Хотя его предназначение связано с пенсионным обеспечением, сам механизм управления предполагает размещение средств в ценные бумаги и депозиты юридических лиц, ГК «Внешэкономбанк», которые могут использовать предоставленные средства в качестве инвестиционного ресурса. Государство может само эмитировать денежные средства, например через механизмы финансирования внутреннего долга, рефинансирования банковского сектора. Эмиссия денег под конкретные инфраструктурные и производственные проекты в форме гарантированных государством облигаций также представляется вопросом политической воли «господствующей коалиции».

У российских физических и юридических лиц имеются финансовые ресурсы, часть которых с помощью рыночных механизмов можно использовать для инвестиций в обновление и техническое перевооружение основных фондов. По данным Национального бюро экономических исследований США, Россия входит в пятерку стран-лидеров, наряду с Саудовской Аравией, ОАЭ, Венесуэлой, по доле финансовых средств относительно ВВП, хранящихся в офшорах. Без учета недвижимости эксперты $N B E R$ оценили российские финансовые активы в сумму 600 млрд. долл. [Alstadsæter, Johannesen, Zucman 2017: 2, 3, 13, 18, 27-32]. Налоговые амнистии, предоставление гарантий защиты инвестиций внутри страны, создание внутренних офшоров в Калининградской обл. и Приморском крае, наряду с антиофшорной кампанией, политически ангажированными ограничениями в отношении российских бизнесменов в Европе и США, могут способствовать возвращению части указанных средств в отечественную экономику. Репатриация капиталов представляет собой тестирование российской политической системы на «лояльность».

Среди крупнейших корпоративных инвесторов выделяются, прежде всего, государственные и частные компании нефтегазового и инфраструктурного секторов. По данным инвестиционного рейтинга «Эксперт РА», топ-10 инвесторов 2018 г. составили: Газпром, Роснефть, ЛУКойл, РЖД, Газпром нефть, Транснефть, Ямал-СПГ, Росатом, Российские сети, Сургутнефтегаз [Рейтинг..

\footnotetext{
1 Налоговая аналитика. Поступления по уровням бюджета за январь-ноябрь 2017-2018 гг. Официальный сайт Федеральной налоговой службы. Доступ: https://analytic.nalog.ru/portal/index.ru-RU. htm (проверено 03.11.2019).

2 Статистика внешнего сектора. - Официальный сайт Центрального Банка РФ. Доступ: http://www. cbr.ru/statistics/?Prtid=svs\&ch=ITM_24647\#CheckedItem (проверено 03.11.2019).

3 Объем Фонда национального благосостояния. - Официальный сайт Министерства финансов РФ. Доступ: https://www.minfin.ru/ru/perfomance/nationalwealthfund/statistics/ (проверено 03.11.2019).
} 
2019: 16]. На основе расчета показателей EBITDA/инвестиции и выручка/инвестиции высокую инвестиционную нагрузку несут 3 государственные компании: Газпром нефть, Российские сети, Транснефть и одна частная - Сургутнефтегаз. Для запуска интенсивного экономического роста «господствующая коалиция» может «подтолкнуть» (стратегия push) крупные компании к увеличению инвестиционной активности посредством формального для государственных компаний и неформального для частных компаний механизма установления минимальной доли прибыли, направленной на финансирование определенных проектов. В частности, по оценкам экспертов, Сургутнефтегаз накопил на долларовых счетах в российских банках сумму, эквивалентную 2,9 трлн руб. ${ }^{1}$ Будучи системным игроком, он в состоянии профинансировать проекты модернизации в нефтепереработке.

Сбережения домохозяйств в виде депозитов физических лиц в коммерческих банках в рублях и валюте составляют 29 трлн руб. ${ }^{2}$ В сложившейся экономической ситуации банки предпочитают кредитовать устойчивый сырьевой бизнес, физических лиц и не готовы вкладываться в проектное финансирование. Возможным инструментом привлечения средств физических лиц в инвестиционные проекты является эмиссия государственных инфраструктурных облигаций, которые могут предлагаться как коммерческим банкам, так и непосредственно физическим лицам.

Две вышеуказанные трансформации экономического роста - усиление факторов интенсивного роста, мобилизация внутренних финансовых ресурсов государства, компаний, домохозяйств - представляются новаторскими, но недостаточными. «Господствующая коалиция» стоит перед новым вызовом: внешнеэкономическая и внешнеполитическая угроза ренте и привилегиям открывает возможность перехода к стратегии «голубого океана» и переходу к интенсивному экономическому росту под непосредственным контролем государства.

На уровне национальной экономики, тесно интегрированной в мировую экономику в качестве сырьевого поставщика, стратегия «голубого океана» предполагает либо перенос акцента на отрасли и проекты внутреннего рынка, которые до того не получали приоритетного государственного и частного финансирования, либо развитие новых проектов и новых рынков внутри традиционных отраслей, открытие в них новых ниш. «Господствующая коалиция» может руководствоваться при выборе отраслей и рынков тремя ориентирами: во-первых, наличием сырьевой, трудовой, технологической базы (поскольку Россия не строит автаркию и может получать необходимую продукцию извне, полное импортозамещение за исключением предприятий ОПК нецелесообразно); во-вторых, необходимостью создать «национальных чемпионов», которые удовлетворят спрос, прежде всего, внутреннего рынка (емкий внутренний рынок амортизирует внешнеэкономические шоки), чтобы быть успешным на внешнем рынке, в-третьих, одновременным развитием рынков торгуемых и неторгуемых товаров/услуг.

Исходя из указанных ориентиров и учитывая общенациональный интерес в увеличении значения факторов интенсивного экономического роста, кото-

\footnotetext{
1 Сургутнефтегаз заработал на падающем рубле. - Ведомости. 29.08.2018. г. Доступ: https://www. vedomosti.ru/business/articles/2018/08/29/779336-surgutneftegaz-zarabotal?utm_campaign=vedomosti public\&utm_content $=779336$-surgutneftegaz-zarabotal\&utm_medium=social\&utm_source =telegram_ved (проверено 03.11.2019).

2 Объем привлеченных кредитными организациями вкладов (депозитов) физических лиц. Официальный сайт Центрального Банка РФ. Доступ: https://www.cbr.ru/statistics/print.aspx?file=bank system/4-2-1a_19.htm\&pid=pdko_sub\&sid=dpbvf (проверено 03.11.2019).
} 
рый способствует повышению уровня и качества жизни всех граждан страны, можно обосновать следующие сегменты «голубого океана».

Сельское хозяйство. В посткрымский период сельское хозяйство стало одним из немногих драйверов роста за счет политического решения о введении продовольственных контрсанкций. Комбинация факторов благоприятствует инвестициям и цифровизации отраслей сельского хозяйства: это потенциал внутреннего спроса (продолжение импортозамещения; как возможная мера - введение продовольственных талонов для бедных граждан страны, которые по официальной статистике составляют 13\% населения ${ }^{1}$, а по оценкам ряда экспертов - в 2 раза больше [Ежемесячный мониторинг.. 2019: 29]); экспортный потенциал (вывоз продукции растениеводства в страны Азии, Африки); наличие трудовых, земельных ресурсов; присутствие в отраслях крупных частных агрохолдингов; работающие механизмы финансовой поддержки «Россельхозбанка»; возможность специализации в нише экологически чистых продуктов. Восстановительный и во многом экстенсивный рост в большинстве отраслей сельского хозяйства закончен, на очереди - повышение эффективности. Одновременно требуются инвестиции в смежные отрасли АПК - в производство сельскохозяйственной техники, перевозку, хранение, переработку, реализацию продукции, строительство объектов АПК. Равномерное развитие смежных отраслей АПК отвечает интересам целой системы и способствует достижению стратегически важной продовольственной безопасности. По прогнозу МЭР, в 2024 г. по сравнению с 2017 г. будет достигнут рост продукции сельского хозяйства на 14,3\%, пищевой промышленности - на $34,1 \%$.

Жилищно-коммунальное хозяйство. Один из немногих секторов экономики, производящий неторгуемые услуги и находящийся на пограничье «белой» и «серой» зоны. Сектор обладает рядом уникальных характеристик: это наличие стабильного платежеспособного спроса; значительный потенциал ресурсосбережения и развития инновационных технологий (ресурсосберегающие технологии, Интернет вещей); присутствие локальных монополий, производящих коммунальные ресурсы; тесные неформальные связи предприятий сектора с муниципальными и региональными властями. Поскольку сектор непосредственно влияет на уровень жизни домохозяйств, его проблемы, такие как утилизация отходов, капитальный ремонт, недобросовестность управляющих компаний, тарифы на услуги ЖКХ, аварийность жилищного фонда, могут быстро стать причинами протестных настроений. Формально сектор показывает невысокую рентабельность: по данным ФНС, рентабельность продаж водоснабжения, утилизации мусора составляет $3,6 \%$; производство, передача и распределение пара и горячей воды имеют отрицательное значение рентабельности; обеспечение электрической энергией, газом и паром $-8,3 \% 2$. Однако при жестком контроле федерального центра за счет выстраивания конкурентных условий оказания услуг, реализации ресурсосберегающих проектов можно трансформировать «коммунальную ренту» в поток инвестиций.

Жилищное строительство. Сектор, который обладает значительным мультипликативным эффектом, т.к. способствует развитию отраслей-смежников и отраслей, производящих комплементарные товары и услуги. Последние

\footnotetext{
1 Численность населения с денежными доходами ниже величины прожиточного минимума и дефицит денежного дохода. - Официальный сайт Федеральной службы государственной статистики. Доступ: http://old.gks.ru/wps/wcm/connect/rosstat_main/rosstat/ru/statistics/population/poverty/\# (проверено 04.02.2019).

2 Среднеотраслевые показатели, характеризующие финансово-хозяйственную деятельность налогоплательщиков за 2017 г. - Официальный сайт Федеральной налоговой службы. Доступ: https:// www.nalog.ru/rn77/taxation/reference_work/conception_vnp/ (проверено 03.11.2019).
} 
новации государственной политики направлены на концентрацию игроковзастройщиков, снос ветхого жилья в рамках программы реновации, установление банковского контроля над жилищным строительством (прекращение схемы долевого строительства, которое нередко вызывало социальные протесты), развитие долгосрочной ипотеки и льготной ипотеки для многодетных семей. Следует отметить, что в рыночной цене жилья заложена «административная рента», и только от воли «господствующей коалиции», которая оказывает влияние на ключевую ставку Банка России, политику крупнейших государственных банков, правила игры в строительной отрасли, зависит реализация массовых инвестиционных проектов страны.

Химия и нефтехимия. Наличие развитой сырьевой базы и технологий позволяют данной отрасли не только масштабировать импортозамещение, увеличить экспорт удобрений, но и перейти к производству продукции более высокой стадии передела. Факторами конкурентоспособности российской продукции химической промышленности на мировом рынке являются относительно низкие издержки основных ресурсов - сырья, электроэнергии, воды, труда. Для реализации проектов в нефтехимии целесообразно подключить инвестиционный ресурс государственных компаний в форме установления доли переработки сырья в РФ для снижения экспорта сырой нефти и газа. Рентабельность отраслей, связанных с химической промышленностью, представляется достаточно привлекательной: производство химических веществ и химических продуктов - 19,8\%; производство резиновых и пластмассовых изделий - 9, $1 \%$; производство прочей неметаллической минеральной продукции - 10,0\%; производство лекарственных средств и материалов, применяемых в медицинских целях, 28,9\%1. Прогноз МЭР предполагает для данной отрасли одни из наиболее высоких темпов прироста - на 49,3\% к 2024 г. по сравнению с 2017 г. [Прогноз... 2018: $53]$.

Образование. Среднее общее и профессиональное, высшее образование в условиях цифровизации, роста доли сферы услуг, сокращения численности трудоспособного населения, увеличения пенсионного возраста приобретает еще более важное значение, чем массовая подготовка кадров для индустриального общества. Приоритетное инвестирование в образование позволяет решить задачи повышения производительности труда, поддержки занятости, овладения цифровыми компетенциями, что выделено в качестве отдельных приоритетных национальных проектов. Реализация проекта 5-100, дорожной карты программы «Цифровая экономика» позволяет рассчитывать на увеличение числа иностранных студентов и доходов от реализации платных образовательных услуг среди абитуриентов из стран СНГ и дальнего зарубежья, что не только является коммерчески выгодным, но и представляет собой компонент политики «мягкой силы».

«Цифровая экономика» представляет собой наиболее яркое проявление стратегии «голубого океана» и предполагает в соответствии с программой «Цифровая экономика Российской Федерации» следующие направления: 1) рынки и отрасли (сферы деятельности); 2) платформы и технологии; 3) среда для развития платформ, технологий, коммуникаций производителей и потребителей рыночных и общественных услуг (институты). Цифровизация экономики как фактор интенсивного роста способствует не только повышению производительности труда, но в рамках концепции Индустрии 4.0 К. Шваба приводит к взаимосвязанным технологическим, социальным, культурным, политиче-

\footnotetext{
1 Среднеотраслевые показатели, характеризующие финансово-хозяйственную деятельность налогоплательщиков за 2017 г. - Официальный сайт Федеральной налоговой службы. Доступ: https:// www.nalog.ru/rn77/taxation/reference_work/conception_vnp/ (проверено 03.11.2019).
} 
ским изменениям. Внедрение новых вычислительных технологий, блокчейна, Интернета вещей, искусственного интеллекта, аддитивного производства, применение разработок биотехнологии, нейротехнологии, генной инженерии, виртуальной реальности, сбор и обработка больших массивов данных представляются не столько технической, сколько ценностной и политической проблемой [Шваб, Дэвис 2018: 45].

Министерство экономического развития РФ прогнозирует с 2021 г. достижение темпов экономического роста в $3 \%$ за счет увеличения инвестиционного спроса (инвестиции в основной капитал должны составить 25\% ВВП), связанного, прежде всего, с реализацией национальных проектов [Прогноз... 2018: 14]. Предложенные автором исследования отраслевых и нишевых «голубых океанов» соответствуют национальным проектам «Образование» (блок «Человеческий капитал»), «Жилье и городская среда» (блок «Комфортная среда для жизни»), «Цифровая экономика», «Производительность труда и поддержка занятости», «Международная кооперация и экспорт» (блок «Экономический рост»).

В заключение можно сделать следующие выводы.

В мировой политической и экономической литературе не сложилось единое мнение о наличии корреляции между типом политического режима и долгосрочными высокими темпами экономического роста. В отечественных исследованиях также нет единства в отношении корреляции эффективности бюджетных инвестиций в отдельные сектора экономики и экономического роста. Автор исследования пришел к заключению, что современная политико-экономическая ситуация на внешней арене несет риск российской «господствующей коалиции» и требует смещения акцентов в сторону приоритетного развития внутреннего рынка, увеличения удельного веса факторов интенсивного экономического роста. В качестве инструментов данной трансформации могут выступить национальные проекты и стратегия «голубого океана», которые мобилизуют внутренние инвестиционные ресурсы для развития отдельных отраслей. Выбор секторов для приоритетного финансирования определяется совокупностью политико-экономических факторов: наличием технологического задела для инноваций, потенциалом внутреннего рынка, максимальным эффектом для отраслей-смежников, повышением качества жизни населения как укреплением легитимности правления «господствующей коалиции». Президентские майские указы 2018 г. каскадируются по целям и сферам в форме 13 национальных проектов, из которых 5 проектов предложены в качестве отраслевых и нишевых «голубых океанов», которые позволят уменьшить зависимость России от колебаний конъюнктуры мировых цен на сырье и будут способствовать развитию факторов интенсивного экономического роста. В конечном счете, успешная реализация данных проектов может рассматриваться как новый «общественный договор» политической и экономической элиты страны с населением, который способствует одновременному удовлетворению частных групп интересов и всеобщего интереса граждан страны.

\section{Список литературы}

Абрамов А.Е., Аксенов И.В., Радыгин А.Д., Чернова М.И. 2018. Современные подходы к измерению государственного сектора: методология и эмпирика. Экономическая политика. Т. 13. № 1. С. 36-69.

Баранов А.О., Крашенина К.С. 2016. Исследование мультипликативного воздействия роста государственных расходов на экономику России. - Проблемы прогнозирования. № 5(158). С. 47-58. Доступ: https://cyberleninka.ru/article/n/ issledovanie-multiplikativnogo-vozdeystviya-rosta-gosudarstvennyh-rashodov-naekonomiku-rossii (проверено 03.11.2019). 
Вотинов А.И., Станкевич И.П. 2017. VAR-подход к оценке эффективности мер фискального стимулирования экономики. - Финансовый журнал / Financial Journal. № 6. C. 64-74.

Ежемесячный мониторинг социально-экономического положения и самочувствия населения 2015 - январь 2019 г.: информационно-аналитический бюллетень. М.: ИНСАП РАНХиГС. Февраль 2019. 31 с. Доступ: https://www.ranepa.ru/images/ News/2019-02/26-02-2019-insap.pdf (проверено 03.11.2019).

Леонова Н.В. 2017. Анализ методики расчета показателя чистого ввоза/вывоза капитала частным сектором в системе эмпирических оценок масштабов бегства капитала. - Деньги и кредит. № 12. С. 40-48.

Норт Д. 1997. Институты, институциональные изменения и функционирование экономики (пер. с англ. А.Н. Нестеренко). М.: Фонд экономической книги «Начала». $180 \mathrm{c}$.

Прогноз социально-экономического развития РФ до 2024 г. М.: Министерство экономического развития РФ. 95 с. Доступ: http://economy.gov.ru/minec/activity/ sections/macro/201801101 (проверено 03.11.2019).

Рейтинг РА «Эксперт» 200 крупнейших инвесторов в российскую экономику. 2019. - Эксnерm. №38(1134).

Чан Ким В., Моборн Р. 2014. Стратегия голубого океана. Как найти или создать рынок, свободный от других игроков? (пер. с англ. И. Ющенко). 4-е изд. М.: Манн, Иванов, Фербер. 304 с.

Шваб К., Дэвис Н. 2018. Технологии Четвертой промышленной революции (пер. с англ. К. Ахметова, А. Врублевского, В. Карпюка, А. Козлова, Ю. Левчука). М.: ЭКСМО. $320 \mathrm{c}$.

Alstadsæter A., Johannesen N., Zucman G. 2017. Who Owns the Wealth in the Tax Havens? Macro Evidence and Implications for Global Inequality: NDRR Working Paper 23805. Cambridge, MA: NDRR. 32 p.

RASTORGUEV Sergei Viktorovich, Dr.Sci. (Pol.Sci.), Professor of the Department of Political Science and Mass Communications, Financial University under the Government of the Russian Federation (49 Leningradsky Ave, Moscow, GSP-3, Russia, 125993; SRastorguev@fa.ru)

\title{
FACTORS, RESOURCES, STRATEGIES OF INTENSIVE ECONOMIC GROWTH OF MODERN RUSSIA: POLITICAL ANALYSIS
}

\begin{abstract}
The article analyzes the prospects of the economic policy of the ruling elite of modern Russia. The existing sectoral structure is determined by the place of Russia in the global division of labor and the trajectory of institutional changes. The author analyzes possibility of the transition of the "dominant coalition" to the replacement of a portion of the income from foreign trade in raw materials with the income from the development of domestic market sectors. The article establishes correlation between the branches of the economy and industry niches selected by the author of the study with priority national projects. The author pays a special attention to the identification of domestic sources of financing projects for the intensification of economic growth on the part of the state, firms, and households. He justifies the conclusion that the Russian Federation has sufficient financial, technological, human resources, raw material potential to achieve a new quality of life for citizens by 2024. To achieve the goals, there is a need for a consensus of elite groups and the implementation of the "easy pushing" strategy of political and economic actors. The author analyzes selection of priority national projects in the framework of the "blue ocean" business concept.

Keywords: factors of intense economic growth, dominant coalition, public investment, domestic market, national projects
\end{abstract}

